\title{
Analysis of economic imbalances under the conditions of regional agrarian markets' integration
}

\author{
Hung Tran $\operatorname{Van}^{1}$, Denis Ushakov ${ }^{2, *}$ \\ ${ }^{1}$ Vietnam National University of Forestry, Dong Nai Province, Vietnam \\ ${ }^{2}$ IC, Suan Sunandha Rajabhat University, 1 U-Thong Nok rd, 10200 Dusit, Bangkok, Thailand
}

\begin{abstract}
At the current stage of economic globalization, the leading factor, among several others, is the intensification of regional economic integration. The share of countries participating in this regional integration covers about $60 \%$ of the world GDP. In this article we apply statistical analysis along with several theoretical approaches to ground and explain the objectivity of convergence and divergence of the national economic systems within the frameworks of integrational unions. We also analyze the trend of economic space asynchronization inside integrations along with the national and regional factors of ongoing regionalization. Our conclusions concern primarily the supranational instruments of participating economies' levelling.
\end{abstract}

\section{Introduction}

Current stage in the development of global economy clearly demonstrates the growing trend of regional economic integration (REI). As of 2019, five largest (as per volumes of mutual export) regional integrations in the world (EU, NAFTA, ASEAN, CIS and MERCOSUR) covered $30 \%$ of the world population, $60 \%$ of the world GDP and over $60 \%$ of the world trade.

Regional economic integration provides all participating countries with additional benefits thanks to expanding distribution markets, preferential access to these markets, more efficient distribution of production factors, lower expenses and much lower risks due to unification of business environment conditions.

Regional integration agreements can be rather different, if taken globally. Bordering countries usually prefer three most common types of regional integration - free trade zones, customs unions or economic unions.

At this, we need to note that regional integration processes make very little exceptions, as both developed and developing countries are taking part in them. This makes the discussion about the relations between the so-called nucleus and periphery even more relevant today. Assessments of regional economic integration influences can be quite different, however - in our opinion - the most important aspect in this discussion is the issue

\footnotetext{
* Corresponding author: denis.us@ssru.ac.th
} 
concerning the gap between developing and developed countries and how it can be narrowed through the policy of economic levelling.

Solving this task is highly important not only for developing countries but for the integrations as a whole. This would allow using the integrational potential to its very maximum as the common, integrated market would be much wider and all preconditions for common customs, currency and economic policies would be formed.

The key goal of our research is to reveal the trends of economic imbalances within the borders of regional integrations along with the factors and consequences of integration practices among the countries with rather asynchronous economic development and very different structures of national economic systems. To achieve this goal the following research tasks have been formulated:

- To provide theoretical explanation for the dynamics of interstate economic integration from the standpoints of both divergence and convergence approaches;

- To describe the specific features of integrations between countries with different levels of economic development;

- To evaluate the convergence and divergence in dynamics as applied to the most wellknown regional integrations;

- To analyze the causes behind imbalances in the development of countries participation in regional integration processes on the examples of the EU, ASEAN and MERCOSUR.

\section{Literature review}

Economic growth is one of the core issues in economic science as such. Discussions concerning long-term growth and how its levels in different countries correlate is closely related to such notions as "convergence" and "divergence". These notions are also widely used in other sciences, apart from economics, including mathematics, medical studies etc.

In economics specifically, convergence (from Latin "convergo" - "coming closer") means countries/regions/groups drawing together in their certain economic parameters, thus reaching a certain average value in these selected parameters.

In its turn, divergence means the opposite process to convergence - when these parameters are becoming more distant in values.

Thus, one of the most interesting questions in the world economy is which of these two trends wins? coming closer or becoming more different? And this question is not just theoretical and philosophical one. The possible answer to this question would surely have important implications for economic policies of all countries since understanding previous trends assumes more accurate forecast of future trends. Will Global South ever become as successful as Global North is today? If convergence is inevitable, then today's wealthy countries do not need to provide financial and other sorts of assistance to poorer countries. And if divergence takes over - then such help will be surely needed. Finally, apart from the winning trend, we must obviously understand the key factors behind these two trends. Leadership of one group of countries and underachievements of other countries can be interpreted through the prism of various instruments: internal economic development of a country itself; country's participation in international trade; international relocation of the production factors; international labour division and so on.

As there are different views on the long-term trends in the development of the world economy, we can determine the presence of at least three scientific schools to date: the school of convergence, the school of reducing divergence and the mixed school.

The school of convergence stems, first and foremost, from the teachings of the neoclassical school of thought and its models of growth which are forecasting the levelling of economies worldwide. 
Chronologically speaking, one of the first among such neoclassical works was R. Solow's model of exogenous growth, according to which production is determined through capital costs, labour costs and technological progress. It is also assumed that there can be some universal, global balance in the state of economy overall. When a country is reaching this balance point, its growth rate are getting slower due to lower output of the production factors [1]. Therefore, the further is a country from this state of balance - the higher is profitability of various production factors in it and also high are its rates of growth [2]. The latter guarantees this country participates actively in the capital outflow/inflow from developed countries into developing ones. According to R. Solow, overcoming economic backwardness is possible through free and equal access to the achievements of the technological progress which is seen as an external factor in relation to economic development.

If the neoclassical model includes international trade, then, according to the model of Heckscher-Ohlin-Samuelson, the levelling in incomes will take place between the owners of the production factors, which means convergence [3].

Generally speaking, participation of countries in regional agreements is expected to provide harmonization between the levels of their economic development through wider distribution of technologies from innovating countries to the countries imitating innovations.

According to R. Vernon theory of the commodity life cycle, development of the most advanced and sophisticated products is normally concentrated in the leading regions which have well developed research and production infrastructure. At the stage of saturation, when the margin income from such products' sales is already going down, advanced productions are usually being relocated to the regions with much lower wages. This is done to reduce production costs, maintaining the same level of income. In such a way, developing territories get a chance to learn and apply the most advanced technological experience, thus becoming closer to the stage of independent development of own innovations. Gradually, wages in such developing regions will be getting higher as well [4].

However, as it was well noted by M. Abramovitz, for this strategy of imitation to become successful, population of a receiving/developing region must have a certain level of the so-called social capability - the inclination to borrow and apply advanced technologies as such. Otherwise, new technologies risk to remain undemanded in a developing country, thus, no matter how advanced and smart this technology is, it will never become the source of economic growth. "Social capability" here is quite a wide notion, it covers: the level of education, the quality of political, financial and business institutes in a society, the openness of the economy etc. [5].

In his turn, A. Gerschenkron put emphasis on the role of public institutes in overcoming economic backwardness [6].

All of the above has direct relation to the capacity of a country to make a breakthrough in its development, however, not every opportunity will actually translate into reality. The rate of overcoming own economic backwardness (that is, the rate of own potential realization) depends on a whole range of factors which are directly influencing the dissemination of knowledge, mobility of the production factors and the rate of the return on capital. Here we need to note that if one of the initial preconditions is violated or missing, the whole development trends may convert from convergence to divergence.

For example, if developed countries would choose NOT to relocate their production facilities to "cheaper" countries at the stage of saturation and instead, would meet the challenges of this stage with active automation of the production processes (which would mean cheaper final product, just as it would have been under the scenario of cheaper labour resources), then the developing countries would automatically lose their opportunity to overcome technological and economic backwardness. 
Finally, the very idea of "catching-up development" has limitations of its own. Once a country is getting closer to the leaders in terms of economic development, its growth rates would be getting lower. This assumption would be true, only if the social capability of this developing country remains the same in quality. Otherwise, the catching-up country would slow down its economic breakthrough or on the opposite - would outstrip yesterday's leaders in development [5].

On their side, the supporters of the school of reducing divergence support the idea that it is very much unrealistic for developing countries to overcome their lagging behind today's world leaders. Studies supporting this statement are usually based on marxist and neoRicardian ideas. Economic backwardness of countries is thus explained mostly by the "vicious circle of poverty" [7].

Another mechanism behind economic backwardness has been presented in the theory of Vanek-Reinert. This theory argues against the absolute benefits of the international trade based on comparative advantages, as described by D. Ricardo [8]. Free trade between developed and developing countries leads to specialization of the former as they are using their competitive advantages in the financial and research fields with constantly growing return, while the former (developing countries) are forced to use primarily their natural advantages, applying them in the most labour-intensive and resource-intensive sectors with the constantly decreasing return [9]. As a result, processing industries in the most underachieving countries become unable to maintain the same competitive level as they fail in competition against foreign commodities at both internal and external markets. Gradually, such sectors in developing countries will become completely exhausted, thus, the countries are losing the whole basis for further industrial and economic breakthrough.

Representatives of the world-system analysis think that the global economy always has a more (economically) developed "nucleus" and a catching-up "periphery", and in their complex relations the nucleus nearly always appropriates a significant part of the peripheral resources using its powers of the world capitalistic center. However, it would be also important to note here that separate countries, with the course of time, can shift from nucleus to the periphery and in the opposite direction, depending on their economic ups and downs. Still, inequality in the world remains roughly the same [10].

D. Rodrik also noted the limited nature of the catching-up development in the contemporary world economy. This researcher put emphasis on the important role the economic leaders of the world are playing in boosting economic growth of the periphery. However, due to the long-lasting consequences of the recent world economic crisis the countries of the nucleus now have to mobilize their resources to support their own economies. This automatically means less support to the developing regions of the global economy. And less support, in turn, means slowing down of the economic growth within the periphery [11].

Studying inequalities in the development of the global economy within the frameworks of the theory of new economic geography covers primarily the issues of productions' allocation and trade interaction between the regions of the world. Copying innovative technologies, underachieving countries are able to become closer to economic leaders [12, 13]. The major problem here is that knowledge, production facilities and transport infrastructure have the tendency to geographical concentration rather than dispersion [14]. This hinders free movement of knowledge between countries and regions and strengthens the system of relations known as nucleus-periphery [15].

The mechanism responsible for levelling the economic development between the countries participating in integrations is based on the idea of distributing economic activities between all the participants of an integration. At this, more developed partners serve as the creators of growth points on the territories of less developed partners through transmission of advanced technologies, investments and so on. 
Still, opportunities for such economic harmonization are not endless or absolute, they are often limited by the available production factors, non-market behavior of some large companies and other circumstances. Deepening inequality is often the consequence of the agglomeration effect. In other words, concentration of economic activities in more developed participants of an integration makes other, less developed participants, unprotected from competition.

Therefore, economic integration as such does not automatically guarantee convergence or divergence effects.

\section{Key results}

Our own theoretical and empirical research allows us formulating three key viewpoints regarding the presence of convergence and divergence trends in the global economy: absolute convergence (countries of the world lean towards one common and equal state, regardless all the preconditions), relative convergence (countries are coming closers in their level of economic development only if the structural parameters of their economies are similar), "clubs of convergence" (groups of countries lean towards several equilibrium conditions, depending on specific structural parameters and certain starting positions) [16, 17].

The analysis we have carried out in relation to economic development levels of the countries participating in regional integrations today has confirmed deepening differentiation in the majority of such regional integrations (see Table 1).

Noteworthy, if we consider the whole period of an integration's existence, a more than ten-fold growth in the average REI GDP per capita is observed in the EU (13,4-fold), CAN (14,8-fold), CACM (23,3-fold), ECCAS (31,7-fold) and ASEAN (43,4-fold). Among these REIs, ECCAS and ASEAN managed to increase the average GDP per capita as compared to the world average by 27,8 and $72 \%$ accordingly. This impressive result of the ASEAN is obviously the best one in the whole collection of data. At the same time, the largest growth of differentiation inside groups is observed in: ASEAN (5,2-fold), COMESA (5,6-fold), EU (7-fold) and ECCAS (12,9-fold).

In case of African REIs such dynamics of the indicators can be explained by rapid economic growth of the selected countries-members which took place due to intensive exploitation of mining locations (for example, oil in Equatorial Guinea and metal ores in Sudan). At the same time, growth in indicators of the ASEAN and EU happened due to their expansion onto less developed countries (Cambodia, Laos, Vietnam and Myanmar in case of the ASEAN; Central and Eastern European countries in case of the EU).

Let us consider in more detail the changes taking place in the economic development levels of countries participating in REIs which practise levelling of economic disproportions through supranational distributary funds: EU, ASEAN, MERCOSUR and CARICOM.

The structure of the European Union has been changing throughout the whole period of its existence. Its expansion at the end of the previous century and especially in the early years of the current century was very much asymmetrical, as new members were seriously lagging behind from the nucleus countries by the levels of their socioeconomic development. Catching-up members of the EU can be divided into two groups, following the chronology of their inclusion. The first group consists of Ireland (joined REI in 1973), Greece (1981), Spain and Portugal (both joined in 1986). The second group consists of 13 countries of the Central and Eastern Europe, all joining in 2004, in 2007 and then in 2013. 
Table 1. Economic inequalities in contemporary regional integrations (Here and further all calculations have been carried out by the author using the statistical materials of the World Bank (www.worldbank.org)).

\begin{tabular}{|c|c|c|c|c|c|c|c|c|}
\hline \multirow{2}{*}{$\begin{array}{c}\text { Regional } \\
\text { economic } \\
\text { integration } \\
\text { s (REIs) }\end{array}$} & \multirow{2}{*}{ 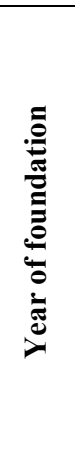 } & \multirow{2}{*}{ 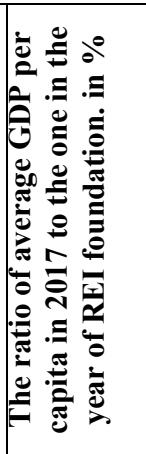 } & \multicolumn{2}{|c|}{$\begin{array}{l}\text { Average GDP } \\
\text { per capita as \% } \\
\text { of the world } \\
\text { GDP per capita }\end{array}$} & \multicolumn{2}{|c|}{$\begin{array}{c}\text { The ratio } \\
\text { between max } \\
\text { and min GDP } \\
\text { per capita } \\
\text { between REI } \\
\text { participants }\end{array}$} & \multicolumn{2}{|c|}{$\begin{array}{c}\text { Ratio of GDP } \\
\text { per capita in } \\
2017 \text { to the one } \\
\text { in the } \\
\text { foundation } \\
\text { year }\end{array}$} \\
\hline & & & 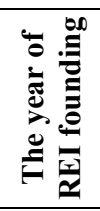 & 독 & 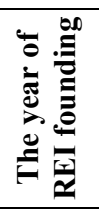 & 국 & 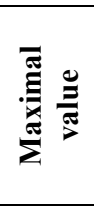 & 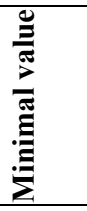 \\
\hline \multicolumn{9}{|c|}{ North. Central and South Americas } \\
\hline CACM & 1961 & 2323.0 & 40.2 & 40.8 & 1.9 & 5.5 & 40.2 & 13.9 \\
\hline $\begin{array}{c}\text { CAN (the } \\
\text { Andean } \\
\text { Community } \\
\text { ) }\end{array}$ & 1969 & 1478.0 & 52.4 & 54.4 & 2.3 & 2.7 & 14.7 & 12.2 \\
\hline CARICOM & 1973 & 930.5 & 88.6 & 90.9 & 11.5 & 27.2 & 6.0 & 2.5 \\
\hline $\begin{array}{c}\text { MERCOSU } \\
\text { R }\end{array}$ & 1991 & 359.8 & 77.1 & 115.2 & 3.6 & 3.7 & 2.9 & 2.7 \\
\hline NAFTA & 1994 & 216.9 & 359.6 & 362.6 & 4.9 & 5.2 & 1.9 & 1.8 \\
\hline \multicolumn{9}{|c|}{ African continent } \\
\hline ECCAS & 1966 & 3166.5 & 31.9 & 59.7 & 4.8 & 61.7 & 45.3 & 3.6 \\
\hline ECOWAS & 1975 & 515.3 & 23.0 & 16.2 & 7.1 & 24.7 & 10.7 & 3.1 \\
\hline COMESA & 1981 & 569.4 & 19.5 & 26.5 & 11.3 & 62.8 & 12.1 & 2.2 \\
\hline UEMOA & 1994 & 269.8 & 6.0 & 7.5 & 3.4 & 3.7 & 2.5 & 2.3 \\
\hline \multicolumn{9}{|c|}{ Eurasia } \\
\hline EU & 1957 & 1338.7 & 318.3 & 334.0 & 2.1 & 14.8 & 26.0 & 3.7 \\
\hline ASEAN & 1967 & 4344.3 & 43.0 & 115.0 & 11.0 & 54.8 & 88.2 & 17.8 \\
\hline $\mathrm{CCC}$ & 1981 & 200.5 & 856.7 & 410.4 & 7.6 & 4.2 & 2.1 & 3.7 \\
\hline CIS & 1991 & 523.1 & 25.8 & 56.1 & 7.3 & 14.1 & 4.3 & 2.2 \\
\hline
\end{tabular}

Note: Due to the lack of data on GDP per capita in El Salvador for the year 1961, the data on CACM for that year is presented without this country. Also, due to the lack of comparable data on GDP per capita for the participants of COMESA and EU in the years of their foundation, the data are taken as: for COMESA - as of 1980 and for the EU - as of 1970.

As the EU expansion was asymmetrical from the very beginning, this Union today has an obvious nucleus and the periphery. In our opinion, the nucleus of the EU is formed by the countries, the average GDP per capita of which is above the EU average. As of 2013, 12 countries of the Union could have passed this criteria - these are the EU-15 but for Greece, Spain and Portugal [18].

MERCOSUR can be seen as a regional integration of the South-South type, since it unites developing countries only. Throughout all 20 years of its existence, this REI always had an obvious outsider - Paraguay. In absolute terms, GDP per capita of this country has been growing all the time, however, if compared to the average value of the whole REI in years, Paraguay's GDP per capita decreased from 57,2\% back in 1991 to 36,0\% in 2013. However, when Bolivia fully joined MERCOSUR, Paraguay lost the status of the least developed countries in this integration. The average GDP per capita in Bolivia during 19912017 was around 23\% from the average value of the whole MERCOSUR. In all other members this indicator is at least equal or above the average value of the union. 
Economic structure in the MERCOSUR members is rather homogenous. Back in 2013, in all these countries, agriculture covered about 5-10\% of the GDP. As expected, in Bolivia and Paraguay the contribution of the primary sector was higher $-13 \%$ and $23 \%$ respectively. Industrial production of this REI creates no less than $25 \%$ of the added value. Services is the leading sector in the economies of all the participants of this South American union (noteworthy, we did not have sufficient and convincing data on the GDP structure of Venezuela as of 2013).

Overall macroeconomic situation in the MERCOSUR countries can hardly be called stable. All these countries were seriously impacted by the crises of the late 1990s - early 2000 s and then by the global financial crisis of 2008. All participants of this bloc are suffering from high inflation and rather high unemployment rates, while their debt load can be called more or less acceptable. Level of unemployment in these countries has been growing during the 1990s, then, around 2002-2003 it reached its peak, demonstrating a two-digits value (the only exception was Bolivia, here the maximum rate of unemployment during the study period was $9,2 \%$ ).

After the crisis of the early 2000s, the share of the unemployed started to go down and during the early 2010 s it stabilized at the level of $6,9-8,5 \%$. Back in 2013 there were two exceptions from this trend - Bolivia with 2,6\% and Brazil, also 2,6\%.

Inflation in the MERCOSUR countries remained to be rather high. In the early 1990s the prices' growth in Brazil was as high as $2000 \%$ per year, however, in the second half of the same decade it was already rather stably fluctuating between the levels of $4 \%$ and $7 \%$. Later on, only 2003 was exceptional in this regard, having 14,7\% of inflation. Uruguay and Venezuela were following roughly the same development scenario. In Argentina and Paraguay the peak of inflation occured during 2002-2003 - 25,9\% and 14,2\% accordingly. In Bolivia the situation was almost the opposite - in 2002 the inflation was minimal, as low as $0,9 \%$ but in 2008 it reached $14 \%$ already.

Paraguay was finishing 2017 with the inflation of 2,7\%, while in Argentina, Bolivia, Brazil and Uruguay inflation was ranging between 5,7\% and 10,6\%. In Venezuela inflation peaked at $38,5 \%$ that year.

From the standpoint of public and private debt volumes at the external market, the most stressful period was observed at the edge of centuries. The total external debts of Uruguay and of Bolivia were around $80-95 \%$ of their GDPs. In Argentina the debt was higher than $100 \%$ of its GDP per three years in a row - from 2002 till 2004. At the same time, in Brazil, Venezuela and Paraguay this indicator was never more than $50 \%$ of their GDPs.

In 2017 the lowest level of the total external debt was observed in Brazil - 13,75\% of the country's GDP and also in Paraguay (17,76\%). In the same year, other countries of the regional integration in question had this indicator ranging from $23 \%$ to $41 \%$.

Socioeconomic indicators of the MERCOSUR members are rather heterogeneous, generally speaking. Argentina, for example, was finishing the year 2017 as a country belonging to the group of high-level human development (49th in the world, out of 187; the Index of Human Development $=0.808$ ). In the same year, three other countries of this bloc had high levels of human development: Uruguay (ranked 50th, IHD $=0.790$ ), Venezuela (ranked 67th; IHD $=0.764$ ) and Brazil (ranked 79th; IHD =0.744). Thus, there were two outsiders in the group - Paraguay (ranked 111th; IHD $=0.676$ ) and Bolivia (ranked 113th; IHD $=0.667)$. These two countries, despite being outsiders in this integration, are still considered to be countries with the average level of human development.

Also noteworthy, in our sample ASEAN is the integration with the widest gaps between the level of economic development. Back in 2013, this gap was as huge as 5480\%! Two rich countries stand out in this REI - Singapore and Brunei. Their GDP per capita indicators (as of 2017) were at the levels of $452 \%$ and $316 \%$ of the ASEAN average accordingly. 
In this REI we can also single out a subgroup - the so-called CLMV: Cambodia, Laos, Myanmar and Vietnam. Since all four countries entered ASEAN, their GDPs per capita grew indeed, yet, they are still the lowest in the group. Back in 2017, as compared to the ASEAN average, their indicators were at $8.3 \%, 13.5 \%, 9.7 \%$ and $15.7 \%$ accordingly.

To sum up,

Numerous empirical studies do not provide a clear-cut and common answer on the question what dominates in the world economy - convergence or divergence trends. At the same time, analysis of the economic development levels in the countries participating in the most influential REIs of the world shows that inequality inside them tends to get more dramatic. One of the key reasons for that is that most of such unions get expanded by means of including less developed countries from the same region. This is equally applicable to the EU, ASEAN and MERCOSUR. Besides that, polarization of the economic development levels between the REIs' members can be sometimes explained by the economic breakthroughs of separate countries, especially if the latter are rich in natural resources (this is especially relevant for CARICOM).

\section{Concluding remarks}

Analysis of the theories of long-term economic growth allows us stating that there are internal and external factors of both convergence and divergence observed in the global economy. To the endogenous/internal factors we can attribute: demand conditions, specificity of supply, institutes, infrastructure etc. And exogenous/external factors are represented by: regulation of external economic activities, foreign business environments in their variety, different accidental factors of influence. This whole combination of the determining factors has permanent and direct influence on the way how a country is developing economically, thus defining its place and rank in the world economy.

We would like to emphasize here that influences of the abovementioned factors can be synchronized (thus, mutually strengthening or mutually weakening each other) or they can be oppositely directed. This makes economic forecasting even more complex. To some extent, a country may control the external effects through its system of public regulation, however, if a country decides to join a REI, such regulation would be inevitably liberalized, as this is the case with nearly all regional integrations.

As a result, in the course of integration, the influence of integration partners is always getting only stronger since external economic barriers in their relations are gradually removed. Under such conditions of free and mutual external economic relations, REI members may impose additional competitive pressure on one another, and none of the involved national economies could be shielded from such negative influences. At the same time, REI members also get additional stimuli for higher growth, since access to many growth resources becomes easier. In other words, any regional integration may have preconditions for both convergence and divergence at the same time.

Analysis of the ratio between the economic development levels of today's REIs' members confirms deepening differentiation in most of regional integrations. The highest growth rates of such socioeconomic segregation are observed in ASEAN (5,2 times), COMESA (5,6 times) and ECCAS (12,9 times).

In the case of African REIs such dynamics can be partially explained by rapid economic growth of the separate countries due to intensive development of their natural resources (oil in Equatorial Guinea, ECCAS or mining ores in Sudan, COMESA). And in the cases of ASEAN and EU, growing differentiation is first of all explained by the inclusion of less developed countries (CLMV in ASEAN and CEE in the EU).

Growing economic inequality in REIs always requires state intrusion. On the one hand, levelling of disproportions allows maximizing all the benefits from liberalized mutual trade 
as markets' capacity is growing and so does the population well-being level. On the other hand, convergence in the economic development levels between the REIs members creates all preconditions for an integration of a higher level (this is a logical consequence of the countries having common economic policies, common strategies and very similar economic interests).

Finally, economic convergence contributes to overall stabilization of REIs. The policy of economic levelling basically means stimulation of economic development in the underachieving participants of a REI, so that to make them closer to the nucleus of an integration. Organizational structure of such a policy is always complex, multilevel, however, the leading role always belongs to supranational bodies. In the course of deepening integration, the latter tend to accumulate traditional state instruments of economic stimulation, such as customs incentives, migration regulation, supervision over foreign investments, control over the currency exchange rates and so on.

In today's global economic practice the goal of economic levelling between the countries-members is officially announced as part of policy in at least five REIs: EU, ASEAN, MERCOSUR, CARICOM and CAN. Noteworthy, three out of these five are the largest regional integrations in today's global economy.

\section{References}

1. R. Solow, The Quarterly Journal of Economics 70(1), 65-94 (1956)

2. J. Taylor, M. Woodford, Handbook of Macroeconomics (Elsevier, North-Holland, 1999)

3. P. Samuelson, The Economic Journal 58(230), 163-184 (1948)

4. R. Vernon, The Quarterly Journal of Economics 80(2), 190-207 (1966)

5. M. Abramovitz, The Journal of Economic History 46(2), 385-406 (1986)

6. A. Gerschenkron, Economic Backwardness in Historical Perspective (Praeger, New York, 1962)

7. G. Myurdall, Modern problems of "the third world" (Progress, Moscow, 1972)

8. E.S. Reinert - Cheltenham, Globalization, Economic Development and Inequality. An Alternative Perspective (Edward Elgar Publishing Ltd., 2004).

9. D. Ushakov, N. Bandurina, S. Shkodinsky, Montenegrin Journal of Economics 13(2), 30-56 (2017)

10. G. Arrighi, T. Hopkins, I. Wallerstein, Antisystemic Movements (London, New York, 2012)

11. D. Rodrik, The Globalization Paradox: Why Global Markets, States, and Democracy Can't Coexist (Oxford University Press, Oxford, 2011)

12. D. Ushakov, I. Elokhova, E. Kozonogova, International Journal of Ecological Economics and Statistics 38(2), 2332 (2017)

13. A.Př́vara, E. Rievajová, M. Yüceşahin, Migration Letter 16(4), 585 - 594 (2019)

14. P. Krugman, "Technology Gap Model” of International Trade. Rethinking International Trade (MIT Press, Cambridge, 2000)

15. G. Ottaviano, D. Puga, Discussion Paper 356 (2009)

16. O. Galor, Economic Journal 106(467), 1056-1069 (1998)

17. D. Quah, Economic Journal 106(437), 1045-1055 (1996)

18. A. Př́ivara, Geographical Journal 71(2), 161-180 (2019) 